\title{
BioMedicine
}

\section{Predictors Of Mortality In Hospitalized COVID-19 Patients: A Mexican Population-Based Cohort Study.}

Follow this and additional works at: https://www.biomedicinej.com/biomedicine

Part of the Life Sciences Commons, Medical Sciences Commons, Other Public Health Commons, Respiratory Tract Diseases Commons, and the Virus Diseases Commons (c) (i)

This work is licensed under a Creative Commons Attribution 4.0 License.

\section{Recommended Citation}

Mesta, Fernando Dr.; Coll, Ángel Mario Dr.; Ramírez, Miguel Ángel M.Sc.; and Delgado-Roche, Livan Dr. (2021) "Predictors Of Mortality In Hospitalized COVID-19 Patients: A Mexican Population-Based Cohort Study.", BioMedicine: Vol. 11 : Iss. 2 , Article 1.

DOI: 10.37796/2211-8039.1124

This Short Communications is brought to you for free and open access by BioMedicine. It has been accepted for inclusion in BioMedicine by an authorized editor of BioMedicine. 


\section{Predictors Of Mortality In Hospitalized COVID-19 Patients: A Mexican Population- Based Cohort Study.}

\section{Cover Page Footnote}

Acknowledgements: The authors want to acknowledge the technical assistance of Arely Riera. Funding: none to declare Author contributions: FM and LDR contributed equally to the conception and design of the study, had full access to all the data and takes responsibility for the integrity and accuracy of statistical analysis. AMCM and MARR contributed with interpretation of data. All the authors contributed equally drafting and critically reviewed the content. All the authors approved the final version to be submitted. Conflicts of interests: the authors declare that they have no conflicts of interest in relation to this study. 


\title{
Predictors of mortality in hospitalized COVID-19 patients: A Mexican population-based cohort study
}

\author{
Fernando Mesta ${ }^{a}$, Angel M. Coll ${ }^{\mathrm{b}}$, Miguel Á. Ramírez ${ }^{\mathrm{b}}$, Livan Delgado-Roche ${ }^{\mathrm{c}, *}$ \\ ${ }^{\text {a }}$ Department of Occupational Health, Safety and Hygiene Research, National Medicine and Homeopathy School of the National \\ Polytechnic Institute, 239 Guillermo Massieu Helguera Ave, La Escalera, 07320, Mexico City, Mexico \\ b AbbVie Farmacéuticos, S.A. de C.V. 3720 Building 3, Office 10-001, Jardines Del Pedregal, 01900, Mexico City, Mexico \\ ${ }^{\mathrm{c}}$ Laboratorios Liomont, S.A. de C.V. 5420-12th Floor, México-Toluca Rd, El Yaqui, Cuajimalpa, 05320, Mexico City, Mexico
}

\begin{abstract}
Objectives: COVID-19 outbreak brings a challenge to healthcare systems. The sex, age, and cardiometabolic comorbidities have been considered risk factors for disease severity. To evaluate the association between risk factors with death as well the risk of death in hospitalized COVID-19 patients.

Methods: The present cross-sectional cohort study, includes hospitalized SARS-CoV-2 confirmed cases. Data analysis was performed using the National COVID-19 Cases Report Database. Pearson's $\chi^{2}$ test and odds ratios (95\% CI) were calculated to determine the association between variables. Thereafter, risk of death was evaluated by Cox proportional hazards model.

Results: A total of 67328 inpatients were included; mean age 55.29 years $( \pm 15.97)$. Of total, $42164(62.62 \%)$ were men, 6 $349(9.43 \%)$ were intubated, and $23873(35.46 \%)$ died. Male sex, age older than 60 years, and cardiometabolic comorbidities were associated with death. Hazard ratio for death in older intubated patients was lower than in non-intubated (HR 1.242, 95\%CI, 1.167-1.322; $P<0.001$ ) and (HR 2.128, 95\%CI, 2.066-2.193; $P<0.001$ ) respectively.

Conclusions: Tracheal intubation or not is the most important predictor for death in COVID-19 infected patients in this Mexican cohort. Already known risk factors for COVID-19 severity may become less relevant once patients require tracheal intubation.
\end{abstract}

Keywords: COVID-19, SARS-CoV-2, Tracheal intubation, Risk factors, Death

\section{Introduction}

$\mathrm{C}$ OVID-19, caused by severe acute respiratory syndrome coronavirus 2 (SARS-CoV-2), shows a global case fatality rate of $4.9 \%$, although in countries like Mexico or Italy has been reported as high as $12.3 \%$ and $14.45 \%$, respectively. At present (July 13th, 2020), COVID-19 has affected 13070590 people and has caused 572428 deaths [1]. Therefore, the ongoing COVID-19 outbreak brings a big challenge to the hospital services, in particular intensive care units (ICU). In order to optimize the availability of ICU resources could be imperative to identify patients at high risk of progressing to severe and critical stages [2]. Tracheal intubation in COVID-19 patients seems to be a risk to physiologically compromised patients [3,4]. In addition, comorbidities including diabetes, obesity, and hypertension have been associated with poor clinical outcomes [5]. An older age, diabetes and history of cardiovascular disease, especially hypertension, but also chronic heart failure and coronary artery disease among others, are between the most important risk factors for COVID-19 mortality [6-8]. In Mexico, as in other developing

Received 25 August 2020; revised 5 October 2020; accepted 11 October 2020.

Available online 01 June 2021.

* Corresponding author at: Laboratorios Liomont, S.A. de C.V. 5420-12th Floor, Mexico-Toluca Rd, El Yaqui, Cuajimalpa, 05320, Mexico City, Mexico.

E-mail addresses: ldelgadoroche@gmail.com, ldelgado@liomont.com.mx (L. Delgado-Roche). 
countries with a high burden of these cardiometabolic comorbidities, the scenario seems to be aggravated $[1,5,6]$. Thus, we aimed to evaluate if age, sex, and preexisting comorbidities are risk factors for death in a Mexican cohort of hospitalized patients, as well as in intubated patients with COVID-19.

\section{Methods}

The present is a cross-sectional cohort study, including adult ( $>18$ years) hospitalized SARS-CoV2 confirmed cases of all ages from February 28th to June 29th, 2020. The infection was confirmed by reverse transcription polymerase chain reaction (RT-PCR), performed according to the protocol approved by the Institute of Epidemiological Diagnosis and Reference [9]. Data analysis was carried out using the National COVID-19 Cases Report Database (Mexican Department of Epidemiology) which is of public access $[9,10]$. Foreign subjects were excluded from the analyses, and incomplete data from the database were eliminated.

\subsection{Statistical Analysis}

The statistical analysis was performed by using the SPSS 24.0 software (IBM, USA). Pearson's $\chi^{2}$ test and odds ratios (OR) with $95 \%$ confidence intervals (CI) were calculated to determine the association between age, sex, tracheal intubation, and comorbidities (diabetes, hypertension and obesity) with death in hospitalized patients. Age was considered as a categorical variable $(<60, \geq 60$ years old) in all the analyses. Thereafter, the risk of death was evaluated by Cox proportional hazards model in intubated patients in comparison with non-intubated patients. Values of $\mathrm{p}<0.05$ were considered statistically significant.

\section{Results}

Until June $29^{\text {th }}, 220657$ SARS-CoV-2 accumulated confirmed cases were registered in Mexico. Of total, $68296(30.95 \%)$ patients have required hospital care. Of total inpatient SARS-CoV-2 confirmed cases, 161 foreigners $(0.24 \%)$ were excluded; and 807 cases $(1.18 \%)$ were eliminated because of incomplete data. Thus, a total of 67328 COVID-19 inpatients were included in the analyses. The mean age was 55.29 years $( \pm 15.97), 42164(62.62 \%)$ were men, and the total number of deaths was $23873(35.46 \%)$. Of hospitalized patients, $6349 \quad(9.43 \%)$ required tracheal intubation. The mean age of intubated patients was 57.16 years $( \pm 15.25), 4292(67.60 \%)$ were males, and $4280(67.41 \%)$ died.

The present analysis showed that sex, age, hypertension, diabetes, obesity, and tracheal intubation were significantly associated with death in COVID-19 hospitalized patients (Table 1).

Survival analysis of hospitalized patients that didn't require tracheal intubation showed that men with SARS-CoV-2 infection had a higher risk of death in comparison with women (HR 1.240, 95\% CI, 1.204 to 1.277; $P<0.001$ ). Age older than 60 years was associated with more than double the risk of mortality (HR 2.128, 95\% CI, 2.066 to $2.193 ; P<0.001$ ). In addition, hypertension (HR 1.257, 95\% CI, 1.218 to 1.297; $P<0.001$ ), diabetes (HR 1.207, 95\% CI, 1.170 to 1.245; $P<0.001$ ), and obesity (HR 1.091, 95\% CI, 1.055 to 1.128; $P<0.001$ ), significantly increased the risk of death in non-intubated hospitalized patients (Fig. 1). In contrast, the sex and hypertension were not associated with an increased risk of death in intubated patients; (HR 1.064, 95\% CI, 0.997 to 1.110; $P=0.062)$ and (HR 1.038, 95\%CI, 0.971 to 1.110 ; $P=0.268)$, respectively. Intubated patients with age older than 60 years, diabetes or obesity had a discrete increased risk of death; (HR 1.242, 95\% CI, 1.167 to $1.322 ; P<0.001$ ), (HR $1.135,95 \% \mathrm{CI}, 1.063$ to

Table 1. Association of age, sex, comorbidities and intubation with death.

\begin{tabular}{|c|c|c|c|c|c|}
\hline \multirow[t]{3}{*}{ Total population: 67328} & \multicolumn{2}{|l|}{ Death, n (\%) } & \multicolumn{3}{|l|}{$\chi^{2}$ test } \\
\hline & \multirow{2}{*}{$\frac{\text { Yes }}{23873(35.5)}$} & \multirow{2}{*}{$\frac{\text { No }}{43455(64.5)}$} & & & \\
\hline & & & OR $(95 \% \mathrm{CI})$ & RR $(95 \%$ CI $)$ & $P$ value \\
\hline Age, $\geq 60$ years, $n(\%)$ & 13528 (19.7) & $14293(21.1)$ & $2.563(2.481-2.647)$ & $1.809(1.773-1.846)$ & $<0.001$ \\
\hline Sex, male, n (\%) & $15676(23.3)$ & $26488(39.3)$ & $1.225(1.185-1.266)$ & $1.141(1.117-1.166)$ & $<0.001$ \\
\hline Hypertension, n (\%) & $10140(15.1)$ & $13011(19.3)$ & $1.728(1.672-1.785)$ & $1.409(1.381-1.438)$ & $<0.001$ \\
\hline Diabetes, n (\%) & $8893(13.2)$ & 11867 (17.6) & $1.580(1.528-1.634)$ & $1.332(1.305-1.359)$ & $<0.001$ \\
\hline Obesity, n (\%) & $5910(8.8)$ & $9981(14.8)$ & $1.103(1.063-1.145)$ & $1.065(1.040-1.090)$ & $<0.001$ \\
\hline Tracheal intubation, $\mathrm{n}(\%)$ & $4280(6.4)$ & $2069(3.1)$ & $4.370(4.135-4.617)$ & $2.098(2.055-2.142)$ & $<0.001$ \\
\hline
\end{tabular}

COVID-19 hospitalized patients with age older than 60 years, male sex, comorbidities history (hypertension, diabetes and obesity) or requiring tracheal intubation were more likely to death than SARS-CoV-2 hospitalized patients without those risk factors. Total population of SARS-CoV-2 confirmed patients hospitalized in Mexico from February 28th to June 29th, 2020, according to National COVID19 Cases Report Database (Mexican Department of Epidemiology). 


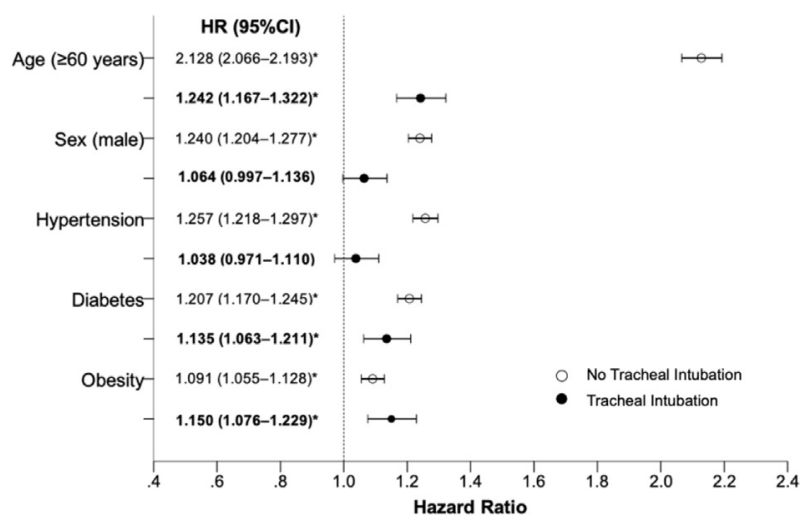

Fig. 1. Hazard ratio for death according to risk factors in hospitalized SARS-CoV-2 patients, according to intubation requirement. HR, hazard ratio. $* P<0.001$.

1.211; $P<0.001$ ), and (HR 1.150, 95\% CI, 1.076 to 1.229; $P<0.001$ ) (Fig. 1).

In addition, the survival analysis showed that the age had a different impact on survival probability between non-intubated and intubated population. In intubated patients, survival probability was drastically diminished regardless of age (Fig. 2).

\section{Discussion}

Retrospective observational studies have shown that patients with COVID-19 who are older, male, or diabetic are at higher risk of requiring intubation $[11,12]$. The association was also pointed out in a cross-sectional cohort study performed in Mexican population, identifying obesity as a risk factor for mechanical ventilation [11]. In the same way, these risk factors, including hypertension have been associated with death in SARS-CoV-2 infected patients [13-15]. However, available data may not be enough to mark safe conclusions on the prognosis of COVID-19 patients who require mechanical ventilation [16].

The present results are in accordance with previous studies that recognize older age, male sex, hypertension, diabetes and obesity as risk factors for death and severity in SARS-CoV-2 patients [17-20]. In addition, here we showed evidence of association between the requirements of tracheal intubation with death in COVID-19 patients. However, the sex and hypertension seem to be clinically irrelevant regarding the risk of death once the patient is intubated. Likewise, the age of intubated patients didn't appear to be as relevant as in non-intubated population. This finding suggests that younger age is not a protective factor in intubated patients as occurs in hospitalized but not intubated population. Obesity, unlike the other evaluated risk factors, showed a higher HR in intubated patients. This may be explained in part by the negative effects of obesity in mechanics of the lungs and airway [21]. In fact, COVID-19 severity has been correlated with higher body mass index [22].

Although the limitations of this cross-sectional cohort study, it may contribute to understand how age, sex, and cardiometabolic risk factors influence COVID-19 outcome in critically ill patients. Of note, some of these risk factors for COVID-19 may

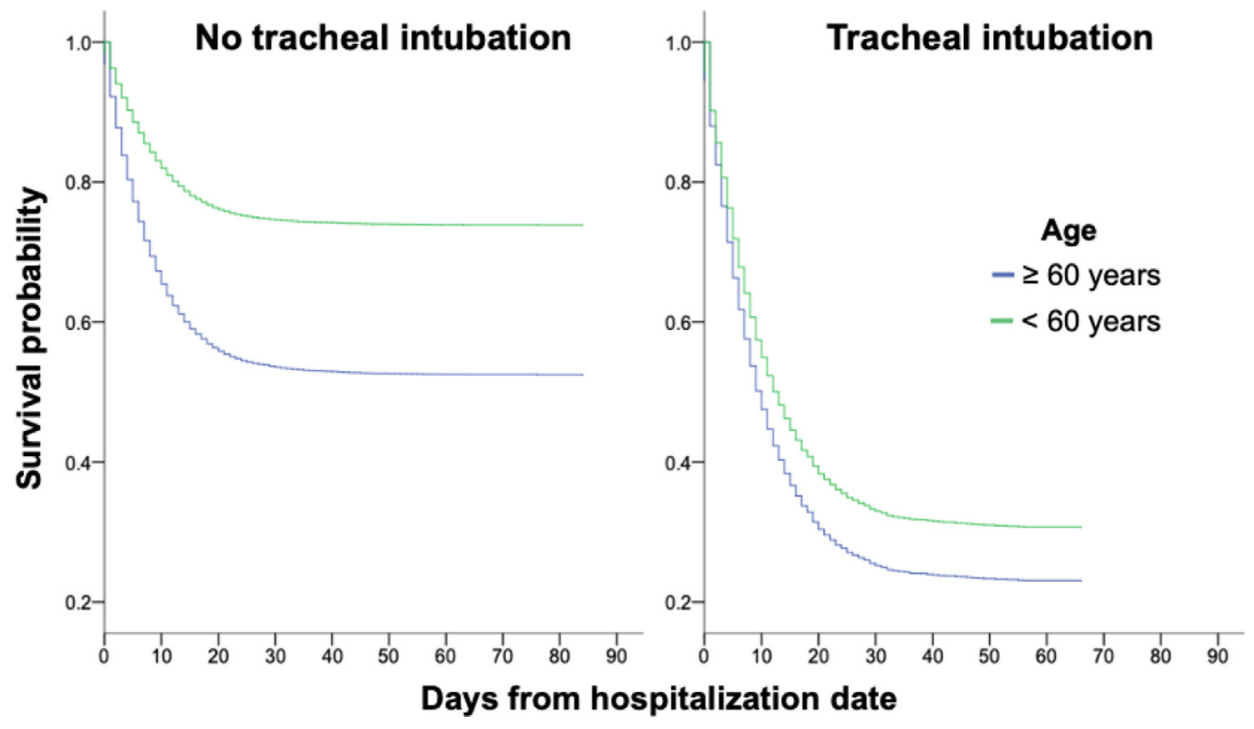

Fig. 2. Survival probability of patients with COVID-19, according to days from hospitalization date, age and intubation requirement. 
become clinically less relevant once patients deteriorate and require TI. Therefore, SARS-CoV-2 infection needs to be widely understood and further evidences regarding the pathophysiology and risk factors are still required.

\section{References}

[1] Johns Hopkins University. Coronavirus COVID-19 Global Cases by the Center for Systems Science and Engineering (CSSE). 2020. https://coronavirus.jhu.edu/map.html. [Accessed 13 July 2020].

[2] Armstrong RA, Kane AD, Cook TM. Outcomes from intensive care in patients with COVID-19: a systematic review and meta-analysis of observational studies. Anaesthesia 2020;75: 1340-9. https://doi.org/10.1111/anae.15201.

[3] Yao W, Wang T, Jiang B, Gao F, Wang L, Zheng H, et al. Emergency tracheal intubation in 202 patients with COVID19 in Wuhan, China: lessons learnt and international expert recommendations. Br J Anaesth 2020;125(1):e28-37.

[4] Auld SC, Caridi M, Blum JM, Robichaux C, Kraft C, Jacob JT, et al. ICU and Ventilator Mortality Among Critically Ill Adults with Coronavirus Disease 2019. Crit Care Med 2020. https://doi.org/10.1097/CCM.0000000000004457. In Press.

[5] Kammar-García A, Vidal-Mayo JJ, Vera-Zertuche JM, Lazcano-Hernández M, Vera-López $\mathrm{O}$, Segura-Badilla $\mathrm{O}$, et al. Impact of comorbidities in Mexican SARS-CoV-2-positive patients: a retrospective analysis in a national cohort. Rev Invest Clin 2020;72(3):151-8. https://doi.org/10.24875/RIC.20000207.

[6] Ceriello A, Standl E, Catrinoiu D, Itzhak B, Lalic NM, Rahelic D, et al. Issues of Cardiovascular Risk Management in People with Diabetes in the COVID-19 Era. Diab Care 2020. https://doi.org/10.2337/dc20-0941.

[7] Saban-Ruiz J, Ly-Pen D. COVID-19: A personalized cardiometabolic approach for reducing complications and costs. The role of aging beyond topics. J Nutr Health Aging 2020: $1-10$.

[8] Dhindsa D, Wong ND, Sperling L. Cardiovascular and cardiometabolic prevention: high-level priority in the era of COVID-19. Cardiovasc Endocrinol Metab 2020;9:125-7.

[9] SSA (Dirección general de Epidemiología, Secretaría de Salud). Datos Abiertos- Dirección General de Epidemiología Secretaría de Salud Gobierno de México. 2020. https://www. gob.mx/salud/documentos/datos-abiertos-152127?idiom=es. [Accessed 29 June 2020].

[10] InDRE (Instituto de Diagnóstico y Referencia Epidemiológicos "Dr. Manuel Martínez Báez"). Lineamientos para la Vigilancia por Laboratorio de la Influenza y otros virus respiratorios. 2017. https://www.gob.mx/cms/uploads/ attachment/file/487580/LVL_Influenza_y_otros_virus_4T. pdf. [Accessed 3 July 2020].

[11] Bello-Chavolla OY, Bahena-López JP, Antonio-Villa NE, Vargas-Vázquez A, González-Díaz A, Márquez-Salinas A, et al. Predicting mortality due to SARS-CoV-2: A mechanistic score relating obesity and diabetes to COVID-19 outcomes in Mexico. J Clin Endocrinol Metab 2020;105(8):1-10. https:// doi.org/10.1210/clinem/dgaa346.

[12] Hur K, Price C, Gray EL, Gulati RK, Maksimoski M, Racette SD, et al. Factors Associated with Intubation and Prolonged Intubation in Hospitalized Patients With COVID19. Otolaryngology-Head and Neck Surgery 2020;163(1): 170-8. https://doi.org/10.1177/0194599820929640.

[13] Yang X, Yu Y, Xu J, Shu H, Xia J, Liu H, et al. Clinical course and outcomes of critically ill patients with SARS-CoV-2 pneumonia in Wuhan, China: a single-centered, retrospective, observational study. Lancet Respir Med 2020;8(5): 475-81. https://doi.org/10.1016/S2213-2600(20)30079-5.

[14] Grasselli G, Zangrillo A, Zanella A, Antonelli M, Cabrini L, Castelli A, et al. Baseline Characteristics and Outcomes of 1591 Patients Infected With SARS-CoV-2 Admitted to ICUs of the Lombardy Region. Italy. JAMA. 2020;323(16):1574-81. https://doi.org/10.1001/jama.2020.5394.

[15] Lippi G, Wong J, Henry BM. Hypertension in patients with coronavirus disease 2019 (COVID-19): a pooled analysis. Pol Arch Intern Med 2020;130(4):304-9. https://doi.org/10.20452/ pamw.15272.

[16] Zareifopoulos N, Lagadinou M, Karela A, Karantzogiannis G, Velissaris D. Intubation and mechanical ventilation of patients with COVID-19: what should we tell them? Monaldi Arch Chest Dis 2020;90(1296):191-2. https:// doi.org/10.4081/monaldi.2020.1296.

[17] Espinosa OA, Zanetti ADS, Antunes EF, Longhi FG, Matos TA, Battaglini PF. Prevalence of comorbidities in patients and mortality cases affected by SARS-CoV2: a systematic review and meta-analysis. Rev Inst Med Trop Sao Paulo 2020;22(62):e43. https://doi.org/10.1590/S16789946202062043.

[18] Grasselli G, Greco M, Zanella A, Albano G, Antonelli M, Bellani G, et al. Risk Factors Associated With Mortality Among Patients With COVID-19 in Intensive Care Units in Lombardy, Italy. JAMA Intern Med 2020:e203539. https:// doi.org/10.1001/jamainternmed.2020.3539.

[19] Zhang J, Wang X, Jia X, Li J, Hu K, Chen G, et al. Risk factors for disease severity, unimprovement, and mortality in COVID-19 patients in Wuhan, China. Clin Microbiol Infect 2020;26(6):767-72. https://doi.org/10.1016/j.cmi.2020.04.012.

[20] Zhou F, Yu T, Du R, Fan G, Liu Y, Liu Z, et al. Clinical course and risk factors for mortality of adult inpatients with COVID-19 in Wuhan, China: a retrospective cohort study. Lancet 2020;395(10220):1054-62. https://doi.org/10.1016/ S0140-6736(20)30566-3.

[21] Dixon A, Peters U. The effect of obesity on lung function. Expert Rev Respir Med 2018;12(9):755-67. https://doi.org/ 10.1080/17476348.2018.1506331.

[22] Simonnet A, Chetboun M, Poissy J, Raverdy V, Noulette J, Duhamel A, et al. High Prevalence of Obesity in Severe Acute Respiratory Syndrome Coronavirus-2 (SARS-CoV-2) Requiring Invasive Mechanical Ventilation. Obesity 2020 Apr;28(7):1195-9. https://doi.org/10.1002/oby.22831. 